4. Holzhey DM, Jacobs S, Mochalski M, Walther T, Thiele H, Mohr F, et al. Sevenyear follow-up after minimally invasive direct coronary artery bypass: experience with more than 1300 patients. Ann Thorac Surg. 2007;83:108-14.
5. Repossini A, Di Bacco L, Nicoli F, Passaretti B, Stara A, Jonida B, et al. Minimally invasive coronary artery bypass: twenty-year experience. J Thorac Cardiovasc Surg. 2019;158:127-38
See Article page 1839.

\section{Commentary: Minimally invasive coronary bypass or percutaneous coronary intervention for complex left anterior descending artery stenosis: A never-ending battle}

Oliver J. Liakopoulos, MD, and

Yeong-Hoon Choi, MD

Percutaneous coronary intervention (PCI) and minimally invasive direct coronary artery bypass grafting (MIDCAB) are both well-established revascularization strategies (Class of Recommendation: I; Level of Evidence: A) for singlevessel disease of the left anterior descending artery (LAD). ${ }^{1}$ Beyond the patient's preference, the choice of the optimal revascularization strategy by the Heart Team should be based on various other factors, including the patient's individual risk profile, coronary anatomy, institutional experience with both procedures, and, ultimately, long-term prognosis. ${ }^{1}$ Consequently, the 2018 Joint Guidelines on Myocardial Revascularization of the European Society of Cardiology and European Association for Cardio-Thoracic Surgery advocate the formation of a "Coronary Heart Team" for patients with suitable coronary anatomy for both procedures (Class of Recommendation: I; Level of Evidence: C). ${ }^{1}$

From the Department of Cardiac Surgery, Kerckhoff Clinic, Campus Kerckhoff, University of Gießen, Bad Nauheim, Germany.

Disclosures: The authors reported no conflicts of interest.

The Journal policy requires editors and reviewers to disclose conflicts of interest and to decline handling or reviewing manuscripts for which they may have a conflict of interest. The editors and reviewers of this article have no conflicts of interest.

Received for publication June 25, 2020; revisions received June 25, 2020; accepted for publication June 26, 2020; available ahead of print July 10, 2020.

Address for reprints: Oliver J. Liakopoulos, MD, Department of Cardiac Surgery, Kerckhoff Clinic, Campus Bad NauheimKerckhoff Clinic, Campus Bad Nauheim, University of GießenBenekestr, 2-8, 61231 Bad Nauheim, Germany (E-mail: o.liakopoulos@kerckhoff-klinik.de).

J Thorac Cardiovasc Surg 2022;163:1850-1

$0022-5223 / \$ 36.00$

Copyright (c) 2020 by The American Association for Thoracic Surgery

http://dx.doi.org/10.1016/j.jtcvs.2020.06.088

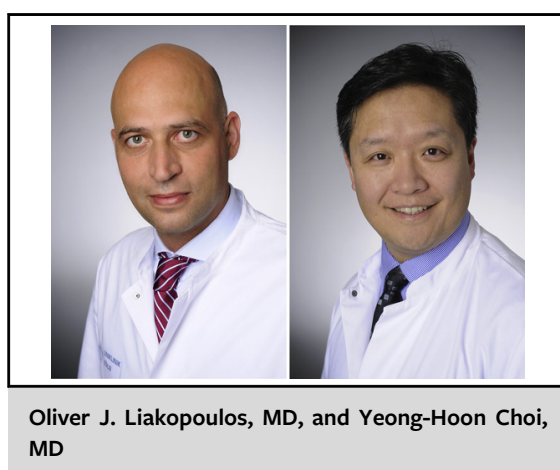

CENTRAL MESSAGE

Revascularization of complex LAD disease with minimally invasive direct coronary artery bypass provides excellent midterm survival, with a low incidence of repeat vessel revascularization.

Observational and randomized-controlled trials comparing early- and mid-term clinical results of MIDCAB versus PCI with drug-eluting stents (DES) for isolated proximal LAD disease uniformly suggest comparable clinical outcomes in terms of mortality, stroke, or myocardial infarction. ${ }^{2-4}$ Hannan and colleagues ${ }^{2}$ reported in 715 propensity score-matched patients undergoing CABG/PCIDES pairs a comparable 3-year mortality $(5.5 \%$ vs $4.8 \%)$ and major adverse cardiocerebral event rate $(7.8 \%$ vs $6.4 \%$ ), respectively. Periprocedural and 12 -month mortality was zero for both groups, whereas 7-year mortality did not differ between MIDCAB or sirolimus-eluting stent in isolated LAD disease (17\% vs $14 \%$ ) in a well-controlled, small-sized randomized-controlled trials. ${ }^{3,4}$ Importantly, both aforementioned trials demonstrate a greater risk for repeat revascularization with DES-PCI, thereby suggesting a long-term superiority of a single left internal thoracic artery graft to the LAD. Indeed, target vessel 
revascularization was required in up to $20 \%$ after PCI at 7 years compared with $1.5 \%$ after MIDCAB in the Leipzig experience $(P<.0001) .{ }^{4}$ In contrast, evidence from a recent meta-analysis by our group failed to show a significant difference for the pooled end-point repeat revascularization when comparing MIDCAB with DES-PCI treatment for isolated LAD disease. $^{5}$

In this issue of the Journal, Patel and colleagues ${ }^{6}$ aimed to further strengthen the evidence for or against the benefit of MIDCAB or DES-PCI for isolated LAD disease. The authors retrospectively compared 158 propensity scorematched patient pairs and, in contrast to previous trials, special focus was set on complex LAD disease and the use of second-generation DES to depict current PCI standards. Mid-term survival was similar after a median follow-up of 5.1 years with $96.2 \%$ and $93.0 \%$ for MIDCAB and PCI, respectively. Importantly, MIDCAB was associated with a significant lower incidence of repeat target vessel revascularization compared with DES-PCI $(2.5 \%$ vs $12.7 \%$; hazard ratio, 3.36 ; $95 \%$ confidence interval, $1.11-10.16 ; P=.032$ ), a finding that persisted independently of the complexity of the LAD lesion. Of interest, cost analysis of either revascularization strategy including all reinterventions resulted into a $17 \%$ lower total cost estimate favoring MIDCAB over DES-PCI.

The results of the present study are in several ways quite unique. This is the first systematic analysis that explicitly includes only patients with complex LAD disease and confirms excellent mid-term survival for both revascularization strategies. Moreover, the clinical outcomes in terms of mortality and repeat revascularization are not compromised by the use of rather outdated PCI approaches (percutaneous transluminal coronary angioplasty, bare-metal stents, or first-generation DES), which is one of the major strengths of this analysis. Finally, this analysis confirms previous studies ${ }^{2-5}$ and clearly underscores the superiority of MIDCAB when directly compared with current DES-PCI practice for complex LAD disease in terms of mid-term durability. Patel and colleagues can be congratulated for their excellent work and for providing further robust evidence for the optimal revascularization strategy of isolated LAD disease that should be taken into account within the decision-making of every Coronary Heart Team.

\section{References}

1. Sousa-Uva M, Neumann FJ, Ahlsson A, Alfonso F, Banning AP, Benedetto U, et al. 2018 ESC/EACTS guidelines on myocardial revascularization. Eur J Cardiothorac Surg. 2019;55:4-90.

2. Hannan EL, Zhong Y, Walford G, Holmes DR Jr, Venditti FJ, Berger PB, et al. Coronary artery bypass graft surgery versus drug-eluting stents for patients with isolated proximal left anterior descending disease. J Am Coll Cardiol. 2014;64: 2717-26.

3. Thiele H, Neumann-Schniedewind P, Jacobs S, Boudriot E, Walther T, Mohr FW, et al. Randomized comparison of minimally invasive direct coronary artery bypass surgery versus sirolimus-eluting stenting in isolated proximal left anterior descending coronary artery stenosis. J Am Coll Cardiol. 2009;53:2324-31.

4. Blazek S, Rossbach C, Borger MA, Fuernau G, Desch S, Eitel I, et al. Comparison of sirolimus-eluting stenting with minimally invasive bypass surgery for stenosis of the left anterior descending coronary artery: 7-year follow-up of a randomized trial. JACC Cardiovasc Interv. 2015;8(1 Pt A):30-8

5. Deppe AC, Liakopoulos OJ, Kuhn EW, Slottosch I, Scherner M, Choi Y-H, et al Minimally invasive direct coronary bypass grafting versus percutaneous coronary intervention for single-vessel disease: a meta-analysis of 2885 patients. Eur $J$ Cardiothorac Surg. 2015;47:397-406

6. Patel NC, Hemli JM, Seetharam K, Singh VP, Scheinerman SJ, Pirelli L, et al Minimally invasive coronary bypass versus percutaneous coronary intervention for isolated complex stenosis of the left anterior descending coronary artery. J Thorac Cardiovasc Surg. 2022;163:1839-46.e1. 